\title{
Incidence and effects of West Nile virus infection in vaccinated and unvaccinated horses in California
}

\author{
Ian A. GARDNER ${ }^{\mathrm{a}}$, Susan J. WONG ${ }^{\mathrm{b}}$, Gregory L. FERRARO ${ }^{\mathrm{c}}$, \\ Udeni B. BALASURIYA ${ }^{\mathrm{d}, \mathrm{e}}$, Pamela J. HULLINGER ${ }^{\mathrm{f}, \mathrm{g}}$, W. David WILSON ${ }^{\mathrm{a}}$, \\ Pei-Yong SHI ${ }^{\mathrm{b}}$, N. James MACLACHLAN ${ }^{\mathrm{d} *}$ \\ ${ }^{a}$ Department of Medicine and Epidemiology, School of Veterinary Medicine, University of California, \\ Davis, CA 95616, USA \\ ${ }^{\mathrm{b}}$ Wadsworth Center, New York State Department of Health, Albany, NY 12201, USA \\ ${ }^{\mathrm{c}}$ Center for Equine Health, School of Veterinary Medicine, University of California, Davis, \\ CA 95616, USA \\ ${ }^{\mathrm{d}}$ Department of Pathology, Microbiology and Immunology, School of Veterinary Medicine, University \\ of California, Davis, CA 95616, USA \\ ${ }^{\mathrm{e}}$ Present address: Department of Veterinary Science, 108 Gluck Equine Research Center, University of \\ Kentucky, Lexington, KY 40546, USA \\ ${ }^{\mathrm{f}}$ California Animal Health and Food Safety Laboratory, School of Veterinary Medicine, University of \\ California, Davis, CA 95616, USA \\ g Present address: Medical Physics and BioPhysics Division, Lawrence Livermore National Lab, 7000 \\ East Avenue, L-211, Livermore, CA 94551, USA
}

(Received 5 May 2006; accepted 29 August 2006)

\begin{abstract}
A prospective cohort study was used to estimate the incidence of West Nile virus (WNV) infection in a group of unvaccinated horses $(n=37)$ in California and compare the effects of natural WNV infection in these unvaccinated horses to a group of co-mingled vaccinated horses $(n=155)$. Horses initially were vaccinated with either inactivated whole virus $(n=87)$ or canarypox recombinant $(n=68) \mathrm{WNV}$ vaccines during 2003 or 2004, prior to emergence of WNV in the region. Unvaccinated horses were serologically tested for antibodies to WNV by microsphere immunoassay incorporating recombinant WNV E protein (rE MIA) in December 2003, December 2004, and every two months thereafter until November 2005. Clinical neurologic disease attributable to WNV infection (West Nile disease (WND)) developed in $2(5.4 \%)$ of 37 unvaccinated horses and in 0 of 155 vaccinated horses. One affected horse died. Twenty one (67.7\%) of 31 unvaccinated horses that were seronegative to WNV in December, 2004 seroconverted to WNV before the end of the study in November, 2005. Findings from the study indicate that currently-available commercial vaccines are effective in preventing WND and their use is financially justified because clinical disease only occurred in unvaccinated horses and the mean cost of each clinical case of WND was approximately 45 times the cost of a 2-dose WNV vaccination program.
\end{abstract}

West Nile virus / horses / vaccination / microsphere immunoassay

\footnotetext{
* Corresponding author:

njmaclachlan@ucdavis.edu
} 


\section{INTRODUCTION}

West Nile virus (WNV) is the cause of West Nile disease (WND), a re-emerging mosquito-transmitted disease of humans and animals $[1,6,7,9,11,18]$. In 1999, WNV was first detected in North America in New York, and subsequently the virus spread throughout Canada, the USA, Mexico and the Caribbean [13, 14, 21]. Horses have been the mammalian species most impacted during the current epidemic of WNV infection in North America, with attendant high morbidity and mortality [20,22,25-28]. WNV was not detected in California until July 2003, when the virus was identified in Culex tarsalis mosquitoes in the Imperial Valley of southeastern California [24]. The virus subsequently spread throughout the entire state in 2004 and 2005 [8]. Despite extensive publicity of the devastating impact of WND in horse populations elsewhere in the USA and the availability of two commercial vaccines to prevent WNV infection [17,19], WNV caused widespread morbidity and mortality in California horses. The California Department of Food and Agriculture (CDFA) reported 540 clinical cases of WND in horses in 2004, of which $230(42.6 \%)$ were fatal, and a further 456 cases in 2005, of which $200(43.9 \%)$ were fatal [8].

Despite the devastating impact of WNV infection in horses, only general estimates of the incidence of clinical disease (approximately 10\%) and case-fatality (approximately 30-60\%) in WNV-infected horses have been published based on retrospective data analysis [5-7, 16, 18, 20,28]. Furthermore, although several studies have noted that some horses vaccinated against WNV respond poorly and that WND can occur in vaccinated animals $[2,10,15,25,26]$, there are no reliable estimates as to the frequency of this phenomenon. The objective of the study reported here was to com- pare the incidence and effects of natural WNV infection in unvaccinated and vaccinated horses in California. To our knowledge, our study represents the first study in the current epidemic of WNV infection in North America to prospectively monitor the clinical and subclinical effects of WNV infection in horses.

\section{MATERIALS AND METHODS}

\subsection{Study design}

From January 2003, an initial cohort of 191 horses, aged from 5 to 20 years and predominantly of Thoroughbred and Quarterhorse breeds, was maintained on 24 ha at the Center for Equine Health (CEH), University of California at Davis, USA. The cohort included 37 unvaccinated horses that were not previously exposed to WNV, and 155 horses that were vaccinated with either inactivated whole virus ([19] West Nile Innovator ${ }^{\circledR}$, Fort Dodge Laboratories, Fort Dodge, IA, USA: $n=87$ ) or canarypox recombinant ([17] Recombitek ${ }^{\circledR}$ Equine West Nile virus vaccine, Merial Limited, Duluth, GA, USA: $n=68) \mathrm{WNV}$ vaccines. Seventy-five horses were initially immunized with inactivated WNV vaccine in February, 2003, and re-immunized (boosted) in March of 2003, 2004 and 2005. Twelve additional horses received only a single immunization with this vaccine in March, 2004; 68 horses were vaccinated in March and April of 2004 with recombinant WNV vaccine and re-immunized in March, 2005. The number of unvaccinated horses was intentionally limited to approximately $20 \%$ of the total number of horses in the study for humane reasons. Vaccinated and unvaccinated horses were co-mingled in groups of 6 to 10 , housed on dry lots or on irrigated pasture, and managed similarly. Horses were evaluated at least daily for clinical signs and vaccination 
reactions by trained animal-health technicians. Blood was collected from horses at monthly intervals and serum was stored at $-20^{\circ} \mathrm{C}$ until tested. All clinical evaluations and serologic testing were done independent of knowledge of vaccination status. Horses that died or were euthanized during the follow-up period were subjected to necropsy examination at the Veterinary Medical Teaching Hospital (VMTH) and the cause of death was determined. The protocol was approved by the Institutional Animal Use and Care Committee.

Horses that developed clinical WND were given supportive care at the VMTH that included being suspended in a sling and intensive treatment with $250 \mathrm{mg}$ Banamine (Schering Plough, Union, NJ, USA) twice daily, hyperimmune plasma (Plasvacc USA Inc., Templeton, CA, USA) and recombinant alpha-interferon (ROFERON, Hoffmann-La Roche Inc., Nutley, NJ, USA).

\subsection{Serum antibody assays for WNV}

The presence of WNV antibodies in horse sera was detected by microsphere immunoassay (MIA) that incorporates recombinant WNV envelope protein ( $\mathrm{rE}$ MIA), as previously described [2]. Briefly, recombinant WNV E protein was covalently conjugated to Multi-Analyte $\mathrm{COOH}$ Microspheres (Luminex Corporation, Austin, TX, USA) and then incubated with individual equine sera followed by biotin-labeled goat anti-equine IgG (Kirkegaard \& Perry Laboratories, Gaithersburg, MD, USA) and streptavidin conjugated R-phycoerythrin. The microspheres were then analyzed in a Luminex 100 instrument (Luminex Corporation, Austin, TX, USA) and the median fluorescence intensity was quantified for 100 microspheres for each sample. Positive and negative control sera were used to establish cutoff fluorescence values as described [2]. Sera collected from the unvaccinated horses in December 2003, December 2004, and every two months thereafter until November 2005 were evaluated for the presence of antibodies to WNV. Sera collected from all vaccinated horses in April and November of 2005 were tested by the same method. These sampling dates were chosen for the vaccinated horses because they coincided with the predicted beginning and end of the WNV transmission season in 2005. Sera collected from the unvaccinated horses were also evaluated for the presence of neutralizing antibodies to WNV by plaque reduction neutralization test (PRNT) at the National Veterinary Services Laboratory (Ames, Iowa, USA) $[3,20]$. The IgM capture ELISA [23] performed at the California Animal Health and Food Safety Laboratory was used to confirm WNV infection in horses that exhibited signs consistent with WND [15, 20].

\subsection{Case definitions}

The case definition for a horse with a putative clinical WND event was presentation with signs consistent with WNV infection and laboratory confirmation by IgM capture ELISA. For subclinical infection, a horse that seroconverted between two subsequent samples (i.e. initially was seronegative and then became seropositive by rE MIA) was considered to be an incident case of WNV and to have seroconverted at the midpoint of the 2-month interval.

\subsection{Statistical analysis}

The proportion of horses with WND was compared between vaccinated and unvaccinated horses by Fisher's exact test with a $P$ value of $<0.05$ considered significant. A $95 \%$ confidence interval (CI) for the proportion of clinical 


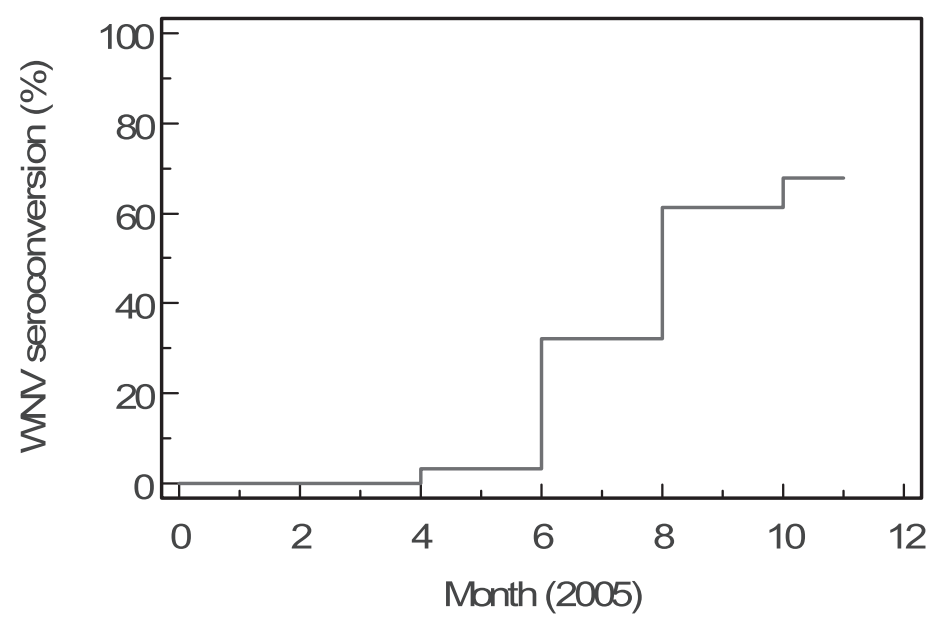

Figure 1. Kaplan-Meier survival curve of WNV seroconversion in 31 unvaccinated horses as evaluated by microsphere immunoassay incorporating recombinant WNV E protein.

cases among horses that seroconverted to WNV was calculated by exact binomial methods. The cumulative probability of WNV seroconversion and the median timeto-seroconversion in unvaccinated horses were estimated using Kaplan-Meier survival methods in MedCalc (MedCalc version 8, Mariakerke, Belgium).

\section{RESULTS}

WNV was first detected in Culex mosquitoes at the study site by WNVspecific polymerase chain reaction in the late summer of 2004 and periodically thereafter (data not shown), which coincided with the initial reported cases of WND in horses in the region [8]. Of the 37 unvaccinated horses, 2 died during 2004 (1 from WND and 1 from colic) and 2 other horses died in 2005 (1 from sole abscess and 1 from colic). All 37 unvaccinated horses were serologically negative to WNV in December, 2003, whereas 4/35 (11.4\%) surviving horses were seropositive in December, 2004. Of the 31 seronegative horses in December 2004, $21(67.7 \%$, SEM = 8.4\%) seroconverted during 2005 with a median time to seroconversion of 8 months (Fig. 1).

Of horses that seroconverted to WNV during either $2004(n=4)$ or $2005(n=21)$, $2(8 \%, 95 \% \mathrm{CI}=1 \%$ to $26 \%)$ developed WND. One affected horse, a 20-year-old Standardbred mare, died in October, 2004, despite intensive treatment and supportive care for 3 days. The horse was confirmed to have WNV infection by IgM capture ELISA, and histologic evaluation of brain tissue collected at necropsy confirmed the presence of encephalomyelitis typical of WNV infection. Tests for rabies and equine herpesvirus (EHV)-1, which were considered to be the most likely differential diagnoses, were negative. The horse was rE-MIA negative at the prior sampling and was not tested at the time of death. Another unvaccinated horse, a 17-year old Mustang, developed severe clinical signs of WND in August, 2005. This horse was initially recumbent but recovered uneventfully after several days of intensive treatment and supportive care. WNV infection 
of this horse also was confirmed by $\operatorname{IgM}$ capture ELISA and the horse was rE MIA positive at all subsequent samplings. No testing for rabies or EHV-1 infection was done. The total diagnostic, treatment, and pathology costs for these two cases were $\$ 2980$ and $\$ 2372$ (mean $=\$ 2$ 676), respectively.

Neurologic disease typical of WNV infection was not observed at any time in any of the 155 vaccinated horses, regardless of vaccine type or frequency of immunization. Two horses that were repeatedly vaccinated with inactivated WNV vaccine failed to seroconvert by April, 2005 (Tab. I), whereas both animals were seropositive in November, suggesting that they were subclinically infected with WNV between April and November of 2005. Similarly, although 7 (58.3\%) of 12 horses that received a single dose of inactivated vaccine were seronegative to the virus in April, 2005, no disease occurred in these animals despite apparent natural infection of at least 3 of these horses as reflected by their seroconversion to $\mathrm{WNV}$ between April and November of 2005. There were no adverse reactions in any of the 155 vaccinated horses. The percentage of clinical cases among vaccinated horses $(0 \%)$ was significantly $(P=0.035)$ less than among nonvaccinated horses $(5.4 \%)$. Six vaccinated horses were euthanized for non-WND illnesses during 2005.

Many (18/64) of the horses that were annually immunized with the recombinant WNV vaccine and were seropositive in April, 2005, became seronegative by November, 2005, as evaluated by rE MIA (Tab. I). Similarly, 6 (8.2\%) of the 73 horses that were annually immunized with the inactivated vaccine that were seropositive in April were seronegative in November, 2005, and $2(50 \%)$ of 4 unvaccinated horses that were seropositive to WNV in December, 2004 as a result of natural infection that year became seronegative by November, 2005.

\section{DISCUSSION}

Findings from the present study confirm that the majority of equine WNV infections are subclinical because only $2(8 \%)$ of the unvaccinated horses that seroconverted to WNV during either 2004 or 2005 exhibited neurologic signs typical of WND. Our results are consistent with prior reports of retrospective studies that indicate that approximately $10 \%$ of WNV-infected horses develop clinical disease $[5,7,16]$, which is markedly greater than the occurrence $(<1 \%)$ of severe disease in WNV-infected humans $[4,7]$. In contrast to the reported attenuation of virulence of WNV in the tropical ecosystems in Latin America and the Caribbean [14], there was no evidence that the virus circulating in California had attenuated following transcontinental spread from the original incursion to New York in 1999 because the frequency of clinical WND in the horses in our study population was similar to that of prior reports. Interestingly, WNV was only sporadically detected by PCR analysis of mosquitoes that were intensively trapped at the site throughout both the 2004 and 2005 WNV seasons, and there was minimal mortality of susceptible bird species at the site (data not shown). These observations suggest that immunologically naïve horses constitute an appropriate sentinel population for detection of the emergence and circulation of WNV in an area, as previously described in southern Africa [12].

The rE MIA provided a rapid and convenient assay for screening large numbers of equine sera for WNV antibodies [2]. The data obtained using the rE MIA were assumed to represent WNV infection because initial seroconversion of unvaccinated horses coincided with the documented emergence of WNV in this region of northern California as reported by the CDFA [8]. Furthermore, antibodies to the related St. Louis encephalitis virus were 
Table I. Serologic status and quantitative test results of WNV vaccinated horses, as determined by microsphere immunoassay incorporating recombinant WNV E protein (rE MIA) in April and November, 2005.

\begin{tabular}{lcccccc}
\hline Vaccine type* & \multicolumn{2}{c}{ April 2005 } & & \multicolumn{2}{c}{ November 2005 } \\
\cline { 3 - 4 } \cline { 6 - 7 } & & No. pos/no. tested (\%) & $\begin{array}{c}\text { rE MIA value } \\
\text { median (range) }\end{array}$ & & No. pos/no. tested (\%) & $\begin{array}{c}\text { rE MIA value } \\
\text { median (range) }\end{array}$ \\
\hline Inactivated & & & & & & \\
& Repeated & $73 / 75(97.3)$ & $7922(21-20748)$ & & $67 / 73(91.8)$ & $2360(63-11667)$ \\
& Single & $5 / 12(41.6)$ & $106(15-2163)$ & & $7 / 12(58.3)$ & $382(10-5640)$ \\
Recombinant & & $68 / 68(100)$ & $3471(208-20195)$ & & $46 / 64(71.9)$ & $909(7-12495)$ \\
\hline
\end{tabular}

* Vaccination of horses was done as described in the text; six vaccinated horses were euthanized between April and November 2005 for illnesses unrelated to WNV.

not identified in any of the horses, and results obtained with the rE MIA were confirmed by WNV PRNT with many of these sera [2]. Our findings also indicate that antibodies to WNV-envelope protein detected by the rE MIA wane over time, which may limit the test's utility as a surveillance tool.

Results of the present study indicate that both currently-available commercial vaccines are effective in preventing WND, as obvious clinical disease occurred only in unvaccinated horses. We believe that the probability of failing to detect a severe WND case was virtually zero because clinical evaluations were done at least daily by highly experienced personnel. It is possible that mild transient infections could have been overlooked, however, the impact of any such cases was considered minimal since treatment was not required. In the present study, there were only two cases of WND and hence the data were too sparse to allow an unequivocal assessment of costs and benefits of vaccination. Nevertheless, it is important to consider the financial ramifications of our findings. In California, the current costs of a 2-dose vaccination program including administration of vaccine are approximately $\$ 60 /$ horse and, hence, the break-even number of horses that could be vaccinated to prevent a single case of WND was approximately 45 susceptible horses, assuming a mean treat- ment cost per case of \$2 676 and 100\% vaccine efficacy. The expected incidence of clinical disease $(2.2 \%)$ used in this calculation was lower than the incidence of WND of $5.4 \%$ in unvaccinated horses observed in the present study. Even if the vaccination program was extended for another year to include an annual booster at $\$ 30 /$ horse, vaccination would still have been a cost-effective decision. Our financial estimates are somewhat speculative, however, because they are based on just two cases in 37 susceptible horses and any variation in WND case numbers would have substantially changed these estimates.

Although WND has been described in horses that were previously vaccinated with inactivated WNV vaccine $[7,15,25,26]$ there was no evidence of disease in vaccinated horses including those that were seronegative to the virus at the beginning of the 2005 WNV season. Furthermore, several of these horses had evidence of infection during 2005 because they seroconverted to WNV between April and November. Because only some $10 \%$ of susceptible horses ever develop clinical WND following infection, additional studies with greater numbers of unvaccinated horses are needed to precisely quantify the costs and benefits of vaccination. However, ethical concerns will likely preclude implementation of such investigations. 


\section{ACKNOWLEDGEMENTS}

The authors thank Laurie Christison and the staff of the Center for Equine Health for sample collection, Valerie Demarest, Josh Boone, Patty Wong and Matt MacLachlan for technical assistance, Ft. Dodge Animal Health and Merial Limited for providing the vaccines, and L. Squared Diagnostics (New Haven, CT, USA) for providing the recombinant West Nile virus envelope protein. Funding source: Center for Equine Health, University of California, Davis, with funds provided by the Maurice Stans Foundation.

\section{REFERENCES}

[1] Autorino G.L., Battisti A., Deubel V., Ferrari G., Forletta R., Giovannini A., Lelli R., Murri S., Scicluna M.T., West Nile virus epidemic in horses, Tuscany region, Italy, Emerg. Infect. Dis. (2002) 8:372-378.

[2] Balasuriya U.B., Shi P.Y., Wong S.J., Demarest V.L., Gardner I.A., Hullinger P.J., Ferraro G.L., Boone J.D., De Cino C.L., Glaser A.L., Renshaw R.W., Ledizet M., Koski R.A., MacLachlan N.J., Detection of antibodies to West Nile virus in equine sera using microsphere immunoassay, J. Vet. Diagn. Invest. (2006) 18:392-395.

[3] Beaty B.J., Calisher C.H., Shope R.E., Diagnostic procedures for viral, rickettsial and chlamydial infections, in: Emmons N.J., Schmidt R.W. (Eds.), Arboviruses, 6th edition, American Public Health Association, Washington, 1989, pp. 797-855.

[4] Briese T., Bernard K.A., West Nile virus - an old virus learning new tricks? J. Neurovirol. (2005) 11:469-475.

[5] Bunning M.L., Bowen R.A., Croop C.B., Sullivan K.G., Davis B.S., Komar N., Godsey M.S., Baker D., Hettler D.L., Holmes D.A., Biggerstaff B.J., Mitchell C.J., Experimental infection of horses with West Nile virus, Emerg. Infect. Dis. (2002) 8:380-386

[6] Cantile C., Di Guardo G., Eleni C., Aripici M., Clinical and neuropathological features of West Nile virus equine encephalomyelitis in Italy, Equine Vet. J. (2000) 32:31-35.
[7] Castillo-Olivares J., Wood J., West Nile virus infection of horses, Vet. Res. (2004) 35:467-483.

[8] CDFA, Animal Health Branch, Equine West Nile site, available at: www.cdfa.ca.gov/ ahfss/ah/wnv_info.htm [consulted 3 July, 2006].

[9] Charrel R.N., Brault A.C., Gallian P. Lemasson J.J., Murgue B., Murri S., Pastorino B., Zeller H., de Chesse R., de Micco P., de Lamballerie X., Evolutionary relationship between Old World West Nile virus strains. Evidence for viral gene flow between Africa, the Middle East, and Europe, Virology (2003) 315:381-388.

[10] Davidson A.H., Traub-Dargatz J.L., Rodeheaver R.M., Ostlund E.N., Pedersen D.D., Moorehead R.G., Stricklin J.B., Dewell R.D., Roach S.D., Long R.E., Albers S.J., Callan R.J., Salman M.D., Immunological responses to West Nile virus in vaccinated and clinically affected horses, J. Am. Vet. Med. Assoc. (2005) 226:240-245.

[11] Durand B., Chevalier V., Pouillot R., Labie J., Marendat I., Murgue B., Zeller H., Zientara S., West Nile virus outbreak in horses, southern France, 2000: results of a serosurvey, Emerg. Infect. Dis. (2002) 8:777-782.

[12] Guthrie A.J., Howell P.G., Gardner I.A., Swanepoel R.E., Nurton J.P., Harper C.K., Pardini A., Groenewald D., Visage C.W., Hedges J.F., Balasuriya U.B., Cornel A.J., MacLachlan N.J., West Nile virus infection of Thoroughbred horses in South Africa, 2000-2001, Equine Vet. J. (2003) 35:601-605.

[13] Hayes C.G., West Nile virus: Uganda, 1937, to New York City, 1999, Ann. NY Acad. Sci. (2001) 951:25-37.

[14] Komar N., Clark G.G., West Nile virus activity in Latin America and the Caribbean, Rev. Panam. Salud Publica (2006) 19:112-117.

[15] Long M.T., Ostlund E.N., Porter M.B., Crom R.L., Equine West Nile encephalitis: Epidemiological and clinical review for practitioners, Proc. Am. Assoc. Equine Pract. (2002) 48:1-6.

[16] Long M.T., Porter M.B., Hernandez J., Giguere S., Fontaine G.L., Jodoin E.A., Gillis K.D., Preliminary data regarding the subclinical exposure rate of horses to West 
Nile virus during the 2001 Florida enzootic, Proc. Am. Assoc. Equine Pract. (2003) 49:397-398.

[17] Minke J.M., Siger L., Karaca K., Austgen L., Gordy P., Bowen R., Renshaw R.W., Loosmore S., Audonnet J.C., Nordgren B., Recombinant canarypoxvirus vaccine carrying the $\mathrm{prM} / \mathrm{E}$ genes of West Nile virus protects horses against a West Nile virusmosquito challenge, Arch. Virol. Suppl. (2004) 18:221-230.

[18] Murgue B., Murri S., Triki H., Deubel V., Zeller H.G., West Nile in the Mediterranean basin: 1950-2000, Ann. NY Acad. Sci. (2001) 951:117-126.

[19] Ng T., Hathaway D., Jennings N., Champ D., Chiang Y.W., Chu H.J., Equine vaccine for West Nile virus, Dev. Biol. (Basel) (2003) 114:221-227.

[20] Ostlund E.N., Crom R.L., Pedersen D.D., Johnson D.J., Williams W.O., Schmitt B.J., Equine West Nile encephalitis, United States, Emerg. Infect. Dis. (2001) 7:665-669.

[21] Petersen L.R., Roehrig J.T., West Nile virus: a reemerging global pathogen, Emerg. Infect. Dis. (2001) 7:611-614.

[22] Porter M.B., Long M.T., Getman L.M., Giguere S., MacKay R.J., Lester G.D., Alleman A.R., Wamsley H.L., Franklin R.P., Jacks S., Buergelt C.D., Detrisac C.J., West Nile virus encephalomyelitis in horses: 46 cases (2001), J. Am. Vet. Med. Assoc. (2003) 222:1241-1247.
[23] Porter M.B., Long M., Gosche D.G., Schott H.M., Hines M.T., Rossano M., Sellon D.C., Immunoglobulin M-capture enzymelinked immunosorbent assay testing of cerebrospinal fluid and serum from horses exposed to West Nile virus by vaccination or natural infection, J. Vet. Intern. Med. (2004) 18:866-870.

[24] Reisen W., Lothrop H., Chiles R., Madon M., Cossen C., Woods L., Husted S., Kramer V., Edman J., West Nile virus in California, Emerg. Infect. Dis. (2004) 10:1369-1378.

[25] Salazar P., Traub-Dargatz J.L., Morley P.S., Wilmot D.D., Steffen D.J., Cunnigham W.E., Salman M.D., Outcome of equids with clinical signs of West Nile virus infection and factors associated with death, J. Am. Vet. Med. Assoc. (2004) 225:267-274.

[26] Schuler L.A., Khaitsa M.L., Dyer N.W., Stoltenow C.L., Evaluation of an outbreak of West Nile virus infection in horses: 569 cases (2002), J. Am. Vet. Med. Assoc. (2004) 225:1084-1089.

[27] Snook C.S., Hyman S.S., Del Piero F., Palmer J.E., Ostlund E.N., Barr B.S., Desrochers A.M., Reilly L.K., West Nile virus encephalomyelitis in eight horses, J. Am. Vet. Med. Assoc. (2001) 218:1576-1579.

[28] Ward M.P., Levy M., Thacker H.L., Ash M., Norman S.K., Moore G.E., Webb P.W., Investigation of an outbreak of encephalomyelitis caused by West Nile virus in 136 horses, J. Am. Vet. Med. Assoc. (2004) 225:84-89. 